\title{
A Prognostic Factor for Prolonged Mechanical Ventilator- Dependent Respiratory Failure after Cervical Spinal Cord Injury : Maximal Canal Compromise on Magnetic Reso- nance Imaging
}

\author{
Subum Lee, Sung Woo Roh, ${ }^{2}$ Sang Ryong Jeon, ${ }^{2}$ Jin Hoon Park, ${ }^{2}$ Kyoung-Tae Kim, ${ }^{3}$ Young-Seok Lee, ${ }^{4}$ Dae-Chul Cho ${ }^{1}$ \\ Department of Neurosurgery, Trauma Center, Kyungpook National University Hospital, School of Medicine, Kyungpook National University, \\ Daegu, Korea \\ Department of Neurosurgery, ${ }^{2}$ Asan Medical Center, University of Ulsan College of Medicine, Seoul, Korea \\ Department of Neurosurgery, ${ }^{3}$ Kyungpook National University Hospital, School of Medicine, Kyungpook National University, Daegu, Korea \\ Department of Neurosurgery, ${ }^{4}$ Kyungpook National University Chilgok Hospital, School of Medicine, Kyungpook National University, Daegu, Korea
}

Objective : The period of mechanical ventilator (MV)-dependent respiratory failure after cervical spinal cord injury (CSCI) varies from patient to patient. This study aimed to identify predictors of MV at hospital discharge (MVDC) due to prolonged respiratory failure among patients with $\mathrm{MV}$ after $\mathrm{CSCl}$.

Methods : Two hundred forty-three patients with CSCl were admitted to our institution between May 2006 and April 2018. Their medical records and radiographic data were retrospectively reviewed. Level and completeness of injury were defined according to the American Spinal Injury Association (ASIA) standards. Respiratory failure was defined as the requirement for definitive airway and assistance of MV. We also evaluated magnetic resonance imaging characteristics of the cervical spine. These characteristics included: maximum canal compromise (MCC); intramedullary hematoma or cord transection; and integrity of the disco-ligamentous complex for assessment of the Subaxial Cervical Spine Injury Classification (SLIC) scoring. The inclusion criteria were patients with CSCI who underwent decompression surgery within 48 hours after trauma with respiratory failure during hospital stay. Patients with Glasgow coma scale 12 or lower, major fatal trauma of vital organs, or stroke caused by vertebral artery injury were excluded from the study.

Results : Out of 243 patients with $\mathrm{CSCl}, 30$ required MV during their hospital stay, and 27 met the inclusion criteria. Among them, $48.1 \%$ (13/27) of patients had MVDC with greater than 30 days MV or death caused by aspiration pneumonia. In total, $51.9 \%$ (14/27) of patients could be weaned from MV during 30 days or less of hospital stay (MV days : MVDC $38.23 \pm 20.79$ vs. MV weaning, $13.57 \pm 8.40 ; p<0.001)$. Vital signs at hospital arrival, smoking, the American Society of Anesthesiologists classification, Associated injury with Injury Severity Score, SLIC score, and length of cord edema did not differ between the MVDC and MV weaning groups. The ASIA impairment scale, level of injury within $\mathrm{C} 3$ to $\mathrm{C6}$, and MCC significantly affected MVDC. The MCC significantly correlated with MVDC, and the optimal cutoff value was $51.40 \%$, with $76.9 \%$ sensitivity and $78.6 \%$ specificity. In multivariate logistic regression analysis, MCC $>51.4 \%$ was a significant risk factor for MVDC (odds ratio, 7.574; $p=0.039$ ).

Conclusion : As a method of predicting which patients would be able to undergo weaning from MV early, the MCC is a valid factor. If the MCC exceeds $51.4 \%$, prognosis of respiratory function becomes poor and the probability of MVDC is increased.

Key Words : Magnetic resonance imaging $\cdot$ Ventilators, Mechanical $\cdot$ Neck injuries $\cdot$ Respiratory insufficiency $\cdot$ Spinal injuries.

- Received : December 11, 2020 •Revised : January 25, 2021 •Accepted : February 2, 2021

- Address for reprints : Dae-Chul Cho

Department of Neurosurgery, Trauma Center, Kyungpook National University Hospital, School of Medicine, Kyungpook National University, 130 Dongdeok-ro, Jung-gu, Daegu 41944, Korea

Tel : +82-53-420-5649, Fax : +82-53-423-0504, E-mail : dccho@knu.ac.kr, ORCID : https://orcid.org/0000-0002-2899-8015

This is an Open Access article distributed under the terms of the Creative Commons Attribution Non-Commercial License (http://creativecommons.org/licenses/by-nc/4.0) which permits unrestricted non-commercial use, distribution, and reproduction in any medium, provided the original work is properly cited. 


\section{INTRODUCTION}

Known risk factors for respiratory failure after cervical spinal cord injury (CSCI) according to several studies are complete spinal cord injury or higher American Spinal Injury Association (ASIA) impairment scale grade; higher anatomic level of injury; and operative treatment ${ }^{6,12,19,20,24)}$. Many patients with high spinal cord injuries require long-term mechanical ventilation (MV) and tracheostomy due to diaphragmatic and accessory respiratory muscle denervation ${ }^{4}$.

Respiratory function in patients with CSCI has been actively researched among researchers including neurocritical care physicians. CSCI carries significant morbidity, mortality, and hospital care costs associated with MV dependence ${ }^{3,8,25)}$. Proper neurocritical care focuses on careful airway management and avoidance of pulmonary complications ${ }^{8,18,25)}$. The period of MV-dependent respiratory failure after CSCI varies from patient to patient. In patients with severe CSCI requiring emergent surgical treatment, risk assessment of respiratory failure is essential to plan proper postoperative care. This could help plan MV weaning, extubation, and short-term airway protection. However, few studies have focused on patients with MV-dependent respiratory failure after CSCI who are more difficult to wean. The guidelines that identify patients with CSCI and warrant weaning and extubation attempts during hospitalization are unclear.

Therefore, the purpose of this study was to identify predictors of MV at hospital discharge (MVDC) due to prolonged respiratory failure among patients who underwent decompression surgery for CSCI. In particular, the role of magnetic resonance imaging (MRI) as a predictive value in respiratory function was evaluated. Through this analysis, we aimed to establish a useful predicting factor for MV weaning during the period of postoperative intensive care.

\section{MATERIALS AND METHODS}

The Institutional Review Board of Kyungpook National University Hospital approved this retrospective study (KNUH IRB 2020-07-033).

\section{Patient enrollment and data collection}

This retrospective cohort study enrolled 243 consecutive patients with CSCI treated in the Department of Neurological Surgery at the Regional Level 1 Trauma Center from May 2006 to April 2018. The inclusion criteria were patients with CSCI who underwent decompression surgery within 48 hours after trauma with respiratory failure during postoperative care. Patients with Glasgow coma scale (GCS) 12 or lower, major fatal trauma of vital organs, stroke caused by vertebral artery injury, and those requiring MV before surgery were excluded.

Clinical data were collected from our institutional electronic medical records. We recorded data of the patients' age, sex, initial vital signs, initial GCS score, underlying disease, smoking status, American Society of Anesthesiologists physical status classification, overall trauma severity according to the Injury Severity Score (ISS), mechanism for trauma, and severity of cord injury according to ASIA grades. To evaluate respiratory function recovery, we recorded data of MV-dependent respiratory failure period, MVDC, and length of intensive care unit (ICU) stay.

\section{Management}

All patients included in this study underwent cord decompression surgery and had respiratory failure during the postoperative care period. MV was used in patients with low oxygen saturation $\left(\mathrm{SaO}_{2}<90 \%\right.$ when $\mathrm{FiO}_{2}>0.6, \mathrm{PaCO}_{2}>50$ $\mathrm{mmHg}$, and $\mathrm{pH}<7.3$ ) and dyspnea. MV dependency was defined as requiring continuous mechanical ventilatory support for 30 or more days. MV weaning was performed in patients who recovered respiratory function and were able to breathe independently.

\section{Radiographic parameters}

MRI of the cervical spine was used in evaluating level of injury; maximum canal compromise $(\mathrm{MCC})^{15)}$; cord contusion; intramedullary hematoma or cord transection; length of cord edema, and integrity of the disco-ligamentous complex (DLC) represented by the Subaxial Cervical Spine Injury Classification (SLIC) scoring ${ }^{16)}$. Regarding measurement of MCC, the anteroposterior canal diameter on midsagittal and axial T2 weighted images at the maximum compromise level were compared with the anteroposterior canal diameter at normal levels immediately above and below the level of injury. Measurements of the normal canal anteroposterior diameter were taken at mid-vertebral body levels (Fig. 1) ${ }^{7,16)}$. MRI scans were 


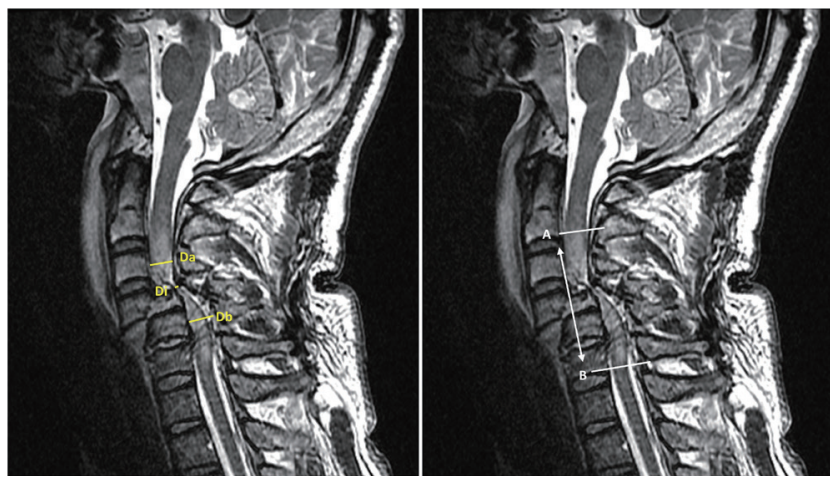

Fig. 1. Measurement of MCC and length of cord edema. Midsagittal T2weighted magnetic resonance imaging with acute traumatic cervical spinal cord injury. Left : $M C C=\left(1-\frac{D i}{(D a+D b / 2}\right) \times 100 \%, D i$ : the anteroposterior canal diameter at the level of maximum injury, Da: the anteroposterior canal diameter at the nearest normal level above the level of injury, $\mathrm{Db}$ : the anteroposterior canal diameter at the nearest normal level below the level of injury. Right : Length of cord edema or sum of cord signal change level. It is measured by the distance from the most cephalic extent $A$ to the most caudal extent $B$ of the injury. MCC : maximum canal compromise.

acquired using the 1.5-T EXCITE ${ }^{\mathrm{TM}}$ whole-body imaging system (General Electric ${ }^{\circledR}$, Milwaukee, WI, USA). T2-weighted images were then obtained using the following imaging sequence: repetition time, $3800 \mathrm{~ms}$; echo time, $102 \mathrm{~ms}$; matrix, 416×224; excitations, four; and field of view, $20 \mathrm{~cm}$. The images were displayed and analyzed using PiView (INFINITT ${ }^{\circledR}$, Seoul, Korea) digital image viewing software.

\section{Statistical analysis}

We compared the clinical and radiologic data between the MVDC and MV weaning groups. Categorical variables in the two groups were expressed as numbers (\%) and were compared using the chi-squared test or Fisher's exact test. Continuous variables were expressed as mean \pm standard deviation and compared using unpaired Student t-tests or Mann-Whitney U-tests, with statistical significance defined as $p<0.05$. The receiver operating characteristic curve was used to determine the best cutoff value of the parameters for predicting MVDC. Kaplan-Meier curves were plotted to compare the MV-dependent respiratory failure period between the groups. Log-rank tests were employed to assess differences in survival between the groups. To adjust for confounders, a multivariate logistic regression analysis was performed of the risk factors associated with MVDC that were identified as significant using a simple logistic regression analysis. The odds ratios of the risk factors associated with MVDC were obtained using the chi-
Table 1. Basic characteristics

\begin{tabular}{lccc}
\hline & $\begin{array}{c}\text { MVDC } \\
(\mathbf{n}=\mathbf{1 3})\end{array}$ & $\begin{array}{c}\text { MV weaning } \\
(\mathbf{n}=\mathbf{1 4})\end{array}$ & $\boldsymbol{p}$-value \\
\hline Age (years) & $60.62 \pm 11.22$ & $57.93 \pm 11.38$ & 0.543 \\
SBP (mmHg) & $116.82 \pm 35.99$ & $96.14 \pm 12.54$ & 0.094 \\
HR (/min) & $72.82 \pm 14.22$ & $81.14 \pm 20.01$ & 0.256 \\
RR (/min) & $19.60 \pm 0.84$ & $19.36 \pm 1.78$ & 0.694 \\
GCS & $14.69 \pm 0.75$ & $14.35 \pm 0.84$ & 0.287 \\
Sex, male: female=22:5 & $11: 2$ & $11: 3$ & 1.000 \\
Underlying disease & & & \\
HTN & 3 & 3 & \\
DM & 3 & 1 & \\
Tuberculosis & 0 & 1 & \\
Cardiac & Angina 2 & 0 & \\
Pulmonary & COPD 1 & 0 &
\end{tabular}

$\begin{array}{ll}\text { Smoking } & 2 \\ \text { Never smoker }(n=5) & 1 \\ \text { Ex-smoker }(n=1) & 4 \\ \text { Current smoker }(n=8) & \end{array}$

ASA

$\begin{array}{lll}1(n=2) & 1 & 1 \\ 2(n=12) & 6 & 6 \\ 3(n=12) & 5 & 7 \\ 4(n=1) & 1 & 0\end{array}$

$\begin{array}{lccc}\text { ISS } & 18.61 \pm 4.29 & 17.21 \pm 6.08 & 0.499 \\ \text { Associated injury } & & & 0.678 \\ \text { Brain }(n=9) & 5 & 4 & \\ \text { Chest }(n=4) & 2 & 2 & \\ \text { None }(n=14) & 6 & 8 & \end{array}$

Mechanism of trauma

MVC

Fall down

Others

$\begin{array}{ll}7 & 9 \\ 4 & 5 \\ 2 & 0\end{array}$

Initial ASIA impairment

scale

$0.025^{*}$

$\begin{array}{lrl}A(n=19) & 12 & 7 \\ B(n=6) & 1 & 5 \\ C(n=1) & 0 & 1 \\ D(n=1) & 0 & 1\end{array}$

Completeness of cord injury

$\begin{array}{lrl}\text { Complete }(\mathrm{n}=19) & 12 & 7 \\ \text { Incomplete }(\mathrm{n}=8) & 1 & 7\end{array}$

Values are presented as mean \pm standard deviation or number unless otherwise indicated. *Statistically significant differences $(p<0.05)$. MVDC: mechanical ventilator at hospital discharge, MV : mechanical ventilator, SBP : systolic blood pressure, HR : heart rate, RR : respiratory rate, GCS : Glasgow coma scale, HTN : hypertension, DM : diabetes mellitus, COPD : chronic obstructive pulmonary disease, ASA : American Society of Anaesthesiologists, ISS : Injury Severity Score, MVC : motor vehicle collision, ASIA : American Spinal Injury Association 
squared test. SPSS version 20 software (IBM Corporation, Armonk, NY, USA) was used for all statistical analyses.

Table 2. Clinical outcomes of respiratory failure

\begin{tabular}{lccc}
\hline & $\begin{array}{c}\text { MVDC } \\
(\mathbf{n}=13)\end{array}$ & $\begin{array}{c}\text { MV weaning } \\
(\mathbf{n}=14)\end{array}$ & p-value \\
\hline Definite air & & & 1.000 \\
$\quad$ Tracheostomy (n=24) & 12 & 12 & \\
$\quad$ Endotracheal tube (n=3) & 1 & 2 & \\
\hline $\begin{array}{l}\text { Time to definitive airway } \\
\text { (days) }\end{array}$ & $2.46 \pm 1.17$ & $3.14 \pm 3.13$ & 0.487 \\
MV period (days) & $38.23 \pm 20.79$ & $13.57 \pm 8.40$ & $<0.001^{*}$ \\
ICU LOS (days) & $33.38 \pm 23.18$ & $17.79 \pm 12.62$ & $0.038^{*}$ \\
\hline Total LOS (days) & $37.92 \pm 23.35$ & $74.86 \pm 56.65$ & $0.039^{*}$ \\
\hline Survival rate & $69.2 \%(9 / 13)$ & $100.0 \%(14 / 14)$ & $0.041^{*}$ \\
\hline
\end{tabular}

Values are presented as mean \pm standard deviation or number unless otherwise indicated. *Statistically significant differences $(p<0.05)$. ${ }^{\dagger}$ Deaths $(n=4)$ : septic shock with pneumonia $(n=3)$ and stress-induced cardiomyopathy with pneumonia $(n=1)$. MVDC : mechanical ventilator at hospital discharge, MV : mechanical ventilator, ICU : intensive care unit, LOS : length of stay

\section{RESULTS}

Out of the 243 patients with CSCI, 27 met the selection criteria. During the hospital stay within 30 days, 14 patients were able to wean from MV, and the remaining 13 were MVDC. Factors that adversely affected the ability of patients to be weaned from MV included higher ASIA grade and complete cord injury. There were no differences in other baseline characteristics between the MV weaning group and the MVDC group (patients' age and sex; vital signs and GCS at hospital arrival; underlying disease; smoking; American Society of Anesthesiologists (ASA) classification, ISS and associated injury, or mechanism for trauma; Table 1).

Tracheostomy was performed in 24 out of 27 patients (MVDC 12/13 and MV weaning 12/14) without significant difference in the ratio of the definitive airway (tracheostomy and endotracheal tube) between the two groups. The time of securing definitive airway was also insignificantly different $(p=0.487)$. In contrast, there were significant differences in the duration of the MV required period $(p<0.001)$, ICU length of

Table 3. Radiologic parameters

\begin{tabular}{|c|c|c|c|}
\hline & $\operatorname{MVDC}(n=13)$ & MV weaning $(n=14)$ & $p$-value \\
\hline Level of maximum cord compression & & & 0.260 \\
\hline C1-2 & 0 & 2 & \\
\hline C3 & 2 & 4 & \\
\hline C4 & 3 & 2 & \\
\hline $\mathrm{C5}$ & 7 & 3 & \\
\hline C6 & 1 & 0 & \\
\hline$C 7$ & 0 & 3 & \\
\hline Injured level & & & $0.041^{*}$ \\
\hline From C3 to C6 & 13 & 9 & \\
\hline Others & 0 & 5 & \\
\hline MCC (\%) & $59.29 \pm 14.45$ & $43.59 \pm 17.54$ & $0.018^{*}$ \\
\hline Sum of T2WI signal change level (length of cord edema, vertebral level) & $3.23 \pm 1.48$ & $2.57 \pm 1.70$ & 0.294 \\
\hline Morphology+DLC score & $4.61 \pm 1.80$ & $4.36 \pm 1.90$ & 0.721 \\
\hline SLIC score & $6.85 \pm 1.77$ & $6.86 \pm 1.83$ & 0.988 \\
\hline MR finding & & & 1.000 \\
\hline Contusion (edema only) & 6 & 6 & \\
\hline Hemorrhage & 5 & 6 & \\
\hline Transection & 2 & 2 & \\
\hline
\end{tabular}

Values are presented as mean \pm standard deviation or number. ${ }^{*}$ Statistically significant differences $(p<0.05)$. MVDC : mechanical ventilator at hospital discharge, MV : mechanical ventilator, MCC : maximum canal compromise, T2WI : T2 weighted image, DLC : disco-ligamentous complex, SLIC : Subaxial Cervical Spine Injury Classification, MR : magnetic resonance 
stay (LOS) ( $p=0.038$ ), and total length of hospitalization ( $p=0.039)$ between the groups. Four patients died, all of whom were in the MVDC group ( $p=0.041)$. The causes of all deaths were related to pneumonia (Table 2).

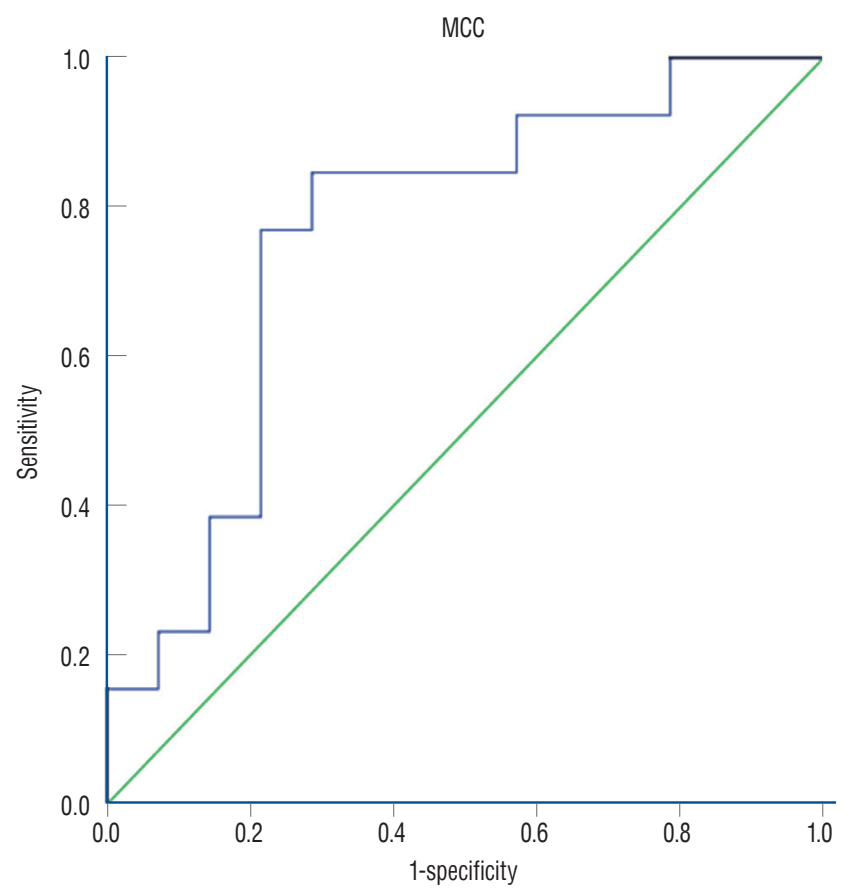

Fig. 2. Receiver operating characteristic curve for mechanical ventilator at hospital discharge. Cutoff value of MCC was $51.40 \%$ with sensitivity 0.769 and specificity 0.786 ( $p=0.020 ; 95 \%$ confidence interval, $0.576-$ 0.952). MCC : maximum canal compromise.

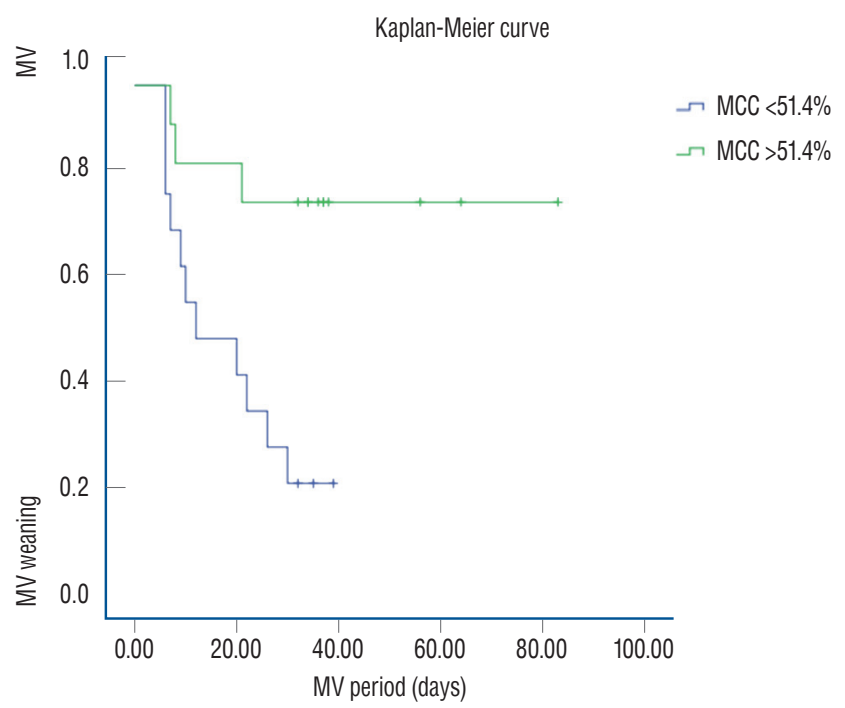

Fig. 3. Kaplan-Meier curve for prediction of MV weaning. MV weaning $(=0)$ and MVDC $(=1)(p=0.004$, log rank test [Mantel-Cox]). MV : mechanical ventilator, MCC : maximum canal compromise.
Regarding radiologic parameters, there were significant differences between the groups in terms of level of neurologic injury from C3 to C6 ( $p=0.041)$ and MCC $(p=0.018)$. The SLICS score and length of cord edema were not significantly different between the two groups. In addition, there were no differences in the morphological plus DLC score among the SLICS scores (Table 3). As a predictor of MVDC, the MCC signifi-

Table 4. Logistic regression analysis of risk factors for MVDC

\begin{tabular}{|c|c|c|}
\hline & Odds ratio $(95 \% \mathrm{Cl})$ & $p$-value \\
\hline \multicolumn{3}{|l|}{$\begin{array}{l}\text { Simple logistic regression } \\
\text { analysis }\end{array}$} \\
\hline Age & $1.023(0.954-1.097)$ & 0.527 \\
\hline \multicolumn{3}{|l|}{ Sex } \\
\hline Male & 1 & \\
\hline Female & $0.667(0.093-4.803)$ & 0.687 \\
\hline \multicolumn{3}{|l|}{ Smoking } \\
\hline Never smoker & 1 & \\
\hline Current \& ex-smoker & $1.562(0.312-7.819)$ & 0.587 \\
\hline ISS & 1.055 (0.908-1.225) & 0.482 \\
\hline SLIC score & $0.996(0.645-1.539)$ & 0.987 \\
\hline MCC (\%) & 1.065 (0.005-1.129) & $0.033^{*}$ \\
\hline \multicolumn{3}{|l|}{ MCC cutoff } \\
\hline$>51.4 \%$ & $12.222(1.990-75.060)$ & $0.007^{*}$ \\
\hline$\leq 51.4 \%$ & 1 & \\
\hline \multicolumn{3}{|l|}{ Injured level } \\
\hline From C3 to C6 & 1 & \\
\hline Others & $0(0.000-0.000)$ & 0.999 \\
\hline \multicolumn{3}{|l|}{ Completeness of injury } \\
\hline Incomplete & 1 & \\
\hline Complete & 12.000 (1.211-118.889) & $0.034^{*}$ \\
\hline \multicolumn{3}{|l|}{ ASIA } \\
\hline A & 1 & \\
\hline B & 0.117 & 0.072 \\
\hline C & 0.000 & 1.000 \\
\hline D & 0.000 & 1.000 \\
\hline \multicolumn{3}{|c|}{$\begin{array}{l}\text { Multivariate logistic regression } \\
\text { analysis }\end{array}$} \\
\hline MCC (51.4\%) & $7.574(1.103-51.989)$ & $0.039^{*}$ \\
\hline Complete injury & $5.712(0.471-69.201)$ & 0.171 \\
\hline
\end{tabular}

${ }^{*}$ Statistically significant differences $(p<0.05)$. MVDC : mechanical ventilator at hospital discharge, $\mathrm{Cl}$ : confidence interval, ISS : Injury Severity Score, SLIC : Subaxial Cervical Spine Injury Classification, MCC : maximum canal compromise, ASIA : American Spinal Injury Association 
cantly correlated with MVDC. The optimal cutoff value of the MCC was $51.40 \%$ ( $p=0.020$ ), with $76.9 \%$ sensitivity and $78.6 \%$ specificity (Figs. 2 and 3 ).

In simple logistic regression analysis, MCC $(p=0.033), \mathrm{MCC}$ exceeding the cut off $(51.4 \%)$ value $(p=0.007)$, and complete cord injury ( $p=0.034)$ were significantly associated with the increased incidence of MVDC (Table 4). We performed multiple logistic regression analysis of the factors that were found to affect MVDC. The result indicated that the MVDC was associated with MCC $>51.4 \%$ (odds ratio, 7.574; $p=0.039$; Table 4).

\section{DISCUSSION}

Elucidating the probability of occurrence and prognosis of respiratory complications after CSCI could aid in their early detection and timely treatment. Therefore, it is necessary to establish a reliable and simple method for identifying prognosis of respiratory failure in postoperative neurocritical care after CSCI. In this study, we identified the prognostic value, regarding patients with MV-dependent respiratory failure outcome, of the features detected on MRI performed acutely following traumatic CSCI. Among the MRI findings, when the MCC exceeded 51.4\%, the likelihood of MVDC was high. In terms of initial clinical parameters for predicting respiratory recovery outcome, ASIA A and complete cord injury patients were challenging to wean from MV, and their associated mortality rate was high. Age, sex, initial vital signs, ASA classification, GCS score, ISS, and smoking did not differ between the MVDC and MV weaning groups.

The phrenic nerve arises from C3 through the C5 spinal nerve. Therefore, diaphragmatic dysfunction is inevitable in patients with injury above C5. CSCI below C5 does not involve the phrenic nerve ${ }^{9,10)}$. However, in this study, MV weaning was significantly more difficult when the level of injury included up to C6. This is because the length of cord signal change in MR of the included patients was about three levels (MVDC 3.23 levels, MV weaning 2.57 levels). Cord injury may increase one or two levels due to bleeding or swelling in the area of the trauma, paralyzing muscles that were not involved initially ${ }^{23)}$.

In a recent review article, the use of high-quality computed tomography (CT) imaging has been shown to be the diagnostic modality of choice in spinal cord injury, and MRI did not clearly add to the diagnostic yield of CT imaging in the initial radiographic evaluation ${ }^{19)}$. Nevertheless, a reliable assessment of spinal cord compression cannot be adequately assessed using CT alone ${ }^{5)}$. With further developments in technology, MRI is becoming the diagnostic gold standard for $\mathrm{CSCI}^{5,7,13,14,21)}$. MRI most clearly visualizes extrinsic spinal cord compression and status of the cord medulla. It also serves to provide prognostic value in terms of neurological recovery. General neurological recovery estimated by Frankel grading was significantly associated with maximal spinal cord compression, length of cord edema, and intramedullary hemorrhage in patients with $\mathrm{CSCI}^{21)}$. By contrast, this study focused only on recovery of respiratory function. The possibility of recovery after MV-dependent respiratory failure showed no difference in the length of cord edema and intramedullary hemorrhage on MRI. We also evaluated the SLIC scoring system ${ }^{22)}$. However, it did not affect weaning from MV, even though the morphology and DLC scores were separated. This shows that external impact energy applied to the subaxial cervical spine structure or instability was not directly related to respiratory function.

The obvious finding that could differentiate between MVDC and MV weaning was MCC on sagittal MRI. We found that $51.4 \%$ or more MCC was a significant independent predictor of MVDC. In a multivariate logistic regression analysis, the patients who exceeded the cut off value (51.4\%) of MCC were 7.6-fold more likely to have MVDC. There was a strong correlation between MCC and ASIA motor score recovery with a minimum one-year follow-up as reported by Aarabi et al. ${ }^{1)}$ They also found an inverse relationship between the degree of canal compromise and follow-up ASIA motor score. Among the various neurologic impairment including limb motor strength after CSCI, respiratory function was the most critical prognostic factor for mortality and hospital discharge without delay ${ }^{2}$. Compared to the clinical outcomes of this study, the MV period, ICU LOS, and total LOS in the MVDC group were significantly longer. The results of this study could help predict the resource, time, and hospital costs required during postoperative $\mathrm{MV}$ treatment in patients who underwent surgery after CSCI.

Lertudomphonwanit et al. ${ }^{12)}$ reported that surgical treatment was a predisposing risk factor of the need for MV in isolated CSCI patients. However, decompression and stabilization were shown to improve neurologic outcomes in cases of cervical spine trauma with proven compression of the spinal $\operatorname{cord}^{11,17)}$. 
The present study only included patients who underwent early surgical treatment. We eliminated the effects of continuous cord compression and cervical instability as quickly as possible. Therefore, the present study was conducted in a highly selective and homogenous patient group who underwent surgical treatment after CSCI. Most patients in modern spinal trauma centers require surgical treatment, and our study may provide useful information for neurocritical management of respiratory function in these patients.

This study has several limitations. First, it was performed at a single center and had a retrospective design. Second, the study population only included patients who underwent surgery, and the sample size was relatively small despite an extensive period of 12 years. Also in demographics, the two patient groups (MVDC and MV weaning) already have had different initial ASIA grade proportions. Third, the effect of tracheostomy was not considered. Finally, we evaluated preoperative MRIs only. It is necessary to analyze not only preoperative images, but also postoperative images. Surgical outcomes and postoperative MRI results may have influenced postoperative respiratory prognosis.

\section{CONCLUSION}

The initial ASIA impairment scale and complete cord injury, ranging from $\mathrm{C} 3$ to $\mathrm{C} 6$ levels, affects respiratory failure in postoperative care after CSCI. The MCC was a significant predictor value of identifying patients likely to need prolonged $\mathrm{MV}$, even when there was no difference in underlying comorbidities such as patient age, ISS, ASA class, GCS, and smoking. If the MCC exceeds 51.4\%, MV weaning becomes difficult within the initial 30 days of hospitalization, and probability of MVDC is high. This could be assessed simply by any neurocritical care worker. In addition, this parameter is helpful for predicting the outcome of respiratory function in patients who underwent emergency surgery after CSCI.

\section{CONFLICTS OF INTEREST}

No potential conflict of interest relevant to this article was reported.

\section{INFORMED CONSENT}

This type of study does not require informed consent.

\section{AUTHOR CONTRIBUTIONS}

\author{
Conceptualization : DCC, SWR, SRJ \\ Data curation : KTK, YSL \\ Formal analysis : JHP, SL \\ Funding acquisition : DCC \\ Methodology : SRJ, JHP \\ Project administration : DCC, KTK \\ Visualization : SWR, YSL \\ Writing - original draft : SL \\ Writing - review \& editing : DCC, JHP, KTK, SL
}

\section{ORCID}

$\begin{array}{ll}\text { Subum Lee } & \text { https://orcid.org/0000-0003-4732-8137 } \\ \text { Sung Woo Roh } & \text { https://orcid.org/0000-0001-6562-4154 } \\ \text { Sang Ryong Jeon } & \text { https://orcid.org/0000-0002-8340-7978 } \\ \text { Jin Hoon Park } & \text { https://orcid.org/0000-0002-0903-3146 } \\ \text { Kyoung-Tae Kim } & \text { https://orcid.org/0000-0003-4867-6854 } \\ \text { Young-Seok Lee } & \text { https://orcid.org/0000-0002-6881-812X } \\ \text { Dae-Chul Cho } & \text { https://orcid.org/0000-0002-2899-8015 }\end{array}$

\section{- Acknowledgements}

This research is supported by the Basic Science Research Program through the National Research Foundation of Korea (NRF-2019R1F1A1064170).

\section{References}

1. Aarabi B, Alexander M, Mirvis SE, Shanmuganathan K, Chesler D, Maulucci $C$, et al. : Predictors of outcome in acute traumatic central cord syndrome due to spinal stenosis. J Neurosurg Spine 14 : 122-130, 2011

2. Berlly $M$, Shem $K$ : Respiratory management during the first five days after spinal cord injury. J Spinal Cord Med 30 : 309-318, 2007

3. Brown R, DiMarco AF, Hoit JD, Garshick E : Respiratory dysfunction and management in spinal cord injury. Respir Care 51 : 853-868; discus- 
sion 869-870, 2006

4. Call MS, Kutcher ME, Izenberg RA, Singh T, Cohen MJ : Spinal cord injury: outcomes of ventilatory weaning and extubation. J Trauma 71 : 1673-1679, 2011

5. Fehlings MG, Rao SC, Tator $\mathrm{CH}$, Skaf G, Arnold P, Benzel E, et al. : The optimal radiologic method for assessing spinal canal compromise and cord compression in patients with cervical spinal cord injury. Part II: results of a multicenter study. Spine (Phila Pa 1976) 24 : 605-613, 1999

6. Grossman RG, Frankowski RF, Burau KD, Toups EG, Crommett JW, Johnson MM, et al. : Incidence and severity of acute complications after spinal cord injury. J Neurosurg Spine 17(1 Suppl) : 119-128, 2012

7. Jeong TS, Lee SG, Kim WK, Ahn Y, Son S : Predictive values of magnetic resonance imaging features for tracheostomy in traumatic cervical spinal cord injury. J Korean Neurosurg Soc 61 : 582-591, 2018

8. Kornblith LZ, Kutcher ME, Callcut RA, Redick BJ, Hu CK, Cogbill TH, et al. : Mechanical ventilation weaning and extubation after spinal cord injury: a Western Trauma Association multicenter study. J Trauma Acute Care Surg 75 : 1060-1069; discussion 1069-1070, 2013

9. Krassioukov A : Autonomic function following cervical spinal cord injury. Respir Physiol Neurobiol 169 : 157-164, 2009

10. Lee DS, Park CM, Carriere KC, Ahn J : Classification and regression tree model for predicting tracheostomy in patients with traumatic cervical spinal cord injury. Eur Spine J 26 : 2333-2339, 2017

11. Lee S, Kim C, Ha JK, Jung SK, Park JH : Comparison of early surgical treatment with conservative treatment of incomplete cervical spinal cord injury without major fracture or dislocation in patients with pre-existing cervical spinal stenosis. Clin Spine Surg 34 : E141-E146, 2021

12. Lertudomphonwanit $T$, Wattanaapisit $T$, Chavasiri C, Chotivichit A : Risk factors relating to the need for mechanical ventilation in isolated cervical spinal cord injury patients. J Med Assoc Thai 97 Suppl 9 : S10S15, 2014

13. Magu S, Singh D, Yadav RK, Bala M : Evaluation of traumatic spine by magnetic resonance imaging and correlation with neurological recovery. Asian Spine J 9 : 748-756, 2015

14. Maynard FM Jr, Bracken MB, Creasey G, Ditunno JF Jr, Donovan WH, Ducker TB, et al. : International standards for neurological and functional classification of spinal cord injury. American Spinal Injury Association.
Spinal Cord 35 : 266-274, 1997

15. Miyanji F, Furlan JC, Aarabi B, Arnold PM, Fehlings MG : Acute cervical traumatic spinal cord injury: MR imaging findings correlated with neurologic outcome--prospective study with 100 consecutive patients. Radiology $243:$ 820-827, 2007

16. Patel AA, Hurlbert RJ, Bono CM, Bessey JT, Yang N, Vaccaro AR : Classification and surgical decision making in acute subaxial cervical spine trauma. Spine (Phila Pa 1976) 35(21 Suppl) : S228-S234, 2010

17. Rosenfeld JF, Vaccaro AR, Albert TJ, Klein GR, Cotler JM : The benefits of early decompression in cervical spinal cord injury. Am J Orthop (Belle Mead NJ) 27 : 23-28, 1998

18. Seidl RO, Wolf D, Nusser-Müller-Busch R, Niedeggen A : Airway management in acute tetraplegics: a retrospective study. Eur Spine J 19 : 1073-1078, 2010

19. Shank CD, Walters $B C$, Hadley MN : Current topics in the management of acute traumatic spinal cord injury. Neurocrit Care $30: 261-271$, 2019

20. Tanaka J, Yugue I, Shiba K, Maeyama A, Naito M : A study of risk factors for tracheostomy in patients with a cervical spinal cord injury. Spine (Phila Pa 1976) 41 : 764-771, 2016

21. Tarawneh AM, D'Aquino D, Hilis A, Eisa A, Quraishi NA : Can MRI findings predict the outcome of cervical spinal cord injury? A systematic review. Eur Spine J 29 : 2457-2464, 2020

22. Vaccaro AR, Hulbert RJ, Patel AA, Fisher C, Dvorak M, Lehman RA Jr, et al. : The subaxial cervical spine injury classification system: a novel approach to recognize the importance of morphology, neurology, and integrity of the disco-ligamentous complex. Spine (Phila Pa 1976) 32 : 2365-2374, 2007

23. Wicks $A B$, Menter RR : Long-term outlook in quadriplegic patients with initial ventilator dependency. Chest $90:$ 406-410, 1986

24. Yang XX, Huang ZQ, Li ZH, Ren DF, Tang JG : Risk factors and the surgery affection of respiratory complication and its mortality after acute traumatic cervical spinal cord injury. Medicine (Baltimore) 96 : e7887, 2017

25. Zimmer MB, Nantwi K, Goshgarian HG : Effect of spinal cord injury on the respiratory system: basic research and current clinical treatment options. J Spinal Cord Med $30:$ 319-330, 2007 